\title{
Clinical study on the indications of procedures for augmenting a large bone defect, as a preparation for the insertion of dental implants
}

\author{
Studiu clinic asupra indicaţiilor procedurilor de augmentare a \\ unui defect osos mare, ca pregătire pentru inserarea implanturilor dentare \\ Mihai Nedelcu', Mihaela Petre ${ }^{2}$, Valentin Sirbu² \\ 'Şcoala Doctorală, Universitatea de Medicină şi Farmacie „Carol Davila“, Bucureşti, România \\ ${ }^{2}$ Facultatea Medicină Dentară, Universitatea de Medicină şi Farmacie „Carol Davila“, Bucureşti, România
}

\begin{abstract}
Most of the time, patients who contact the dentist for the insertion of dental implants have old edentulous areas characterized by marked atrophies. This implies that in these cases, implants of very small size, whose prognosis is not favorable, can be inserted wherever possible. The alternative is the use of bone support surgery. There are several such types of interventions, each addressing a particular clinical situation. Thus, in bone defects of dehis-cence or fenestration, interventions such as GBR augmentation may be used. In the case of horizontal defects, GBR, autogenous bone grafting or bone splitting can be used, and in the case of vertical defects, GBR performed at the same time or before implant insertion, or autogenous bone grafting can be used.
\end{abstract}

Keywords: bone defects, bone splitting, GBR, autogenous bone graft

\section{REZUMAT}

De cele mai multe ori, pacienţii care se adresează medicului stomatolog pentru inserarea implanturilor dentare prezintă zone edentate vechi, caracterizate prin atrofii marcate. Aceasta presupune că în aceste cazuri se pot insera, atunci când se poate, implanturi de dimensiuni foarte mici, al căror prognostic nu este unul favorabil. Alternativa constă în utilizarea unor intervenţii chirurgicale de îmbunătăţire a suportului osos. Există mai multe astfel de tipuri de intervenţii, fiecare adresându-se unei situaţii clinice aparte. Astfel, în defecte osoase de tip dehiscenţă sau fenestraţie, se pot utiliza intervenţii de genul augmentărilor osoase prin tehnica GBR. În cazul defectelor orizontale, se pot utiliza GBR, grefare cu os autogen sau bone splitting, iar în cazul defectelor verticale, se pot folosi GBR - realizată în acelaşi timp operator sau înainte de inserarea implanturilor - sau grefare de os autogen.

Cuvinte cheie: defecte osoase, bone splitting, GBR, grefă de os autogen

\section{NOŢIUNI GENERALE}

În cazul pacienţilor care se prezintă la cabinetul de medicină dentară după o perioadă lungă de timp în care au fost edentaţi, crestele edentate prezintă grade avansate de resorbţie osoasă, instalată în decursul perioadei de edentaţie, din cauza lipsei stimulului funcţional reprezentat de absenţa dinţilor.

Toţi aceşti pacienţi suferă, din punct de vedere fizic şi psihologic, din cauza lipsei dentare şi, pro- babil, singura posibilitate de a restaura protetic zona edentată este aceea de a realiza un tratament implanto-protetic.

Pentru ca acesta să nu se transforme într-un eşec, înainte de inserarea implanturilor, se impune realizarea unor intervenţii de completare a suportului osos, adică de augmentare a defectelor osoase, care de cele mai multe ori au dimensiuni mari.

De-a lungul timpului, s-au descris mai multe tipuri de intervenţii chirurgicale, care au toate, ca 
scop final, aducerea suportului osos la un nivel care să permită inserarea implanturilor fără riscuri şi integrarea tisulară a acestora.

Utilizarea diferitelor proceduri de mărire a ofertei osoase se bazează pe o proprietate esenţială a osului, şi anume capacitatea acestuia de a suferi o etapă de remodelare în cadrul procesului de regenerare osoasă (1).

Există intervenţii chirurgicale variate, precum regenerarea osoasă ghidată (GBR), utilizarea grefelor sub formă de blocuri osoase sau expansiunea osoasă (ridge splitting), prin care se poate interveni, în sensul îmbunătăţirii, atât asupra dimensiunii verticale, cât şi asupra dimensiunii orizontale a osului.

Regenerarea osoasă ghidată este un proces ce permite creşterea osoasă şi, în acelaşi timp, evită plonjarea ţesuturilor moi către zona grefată (2).

Această procedură are la bază principiul conform căruia, prin utilizarea unei membrane, în scop de barieră celulară, se menţine, pentru o perioadă de timp, spaţiul peste un defect vertical sau orizontal. În acest fel se stimulează proliferarea celulelor osteogenice şi se evită migrarea celulelor nedorite din zonele de ţesut moale învecinate.

Prin rolul său de barieră, facilitează menţinerea cheagului sanguin şi stimulează vindecarea osoasă mai rapidă.

Tehnica poate fi utilizată în asociere cu intervenţiile de inserare de implanturi, pentru augmentarea crestelor edentate cu deficit osos, sau în cazu-

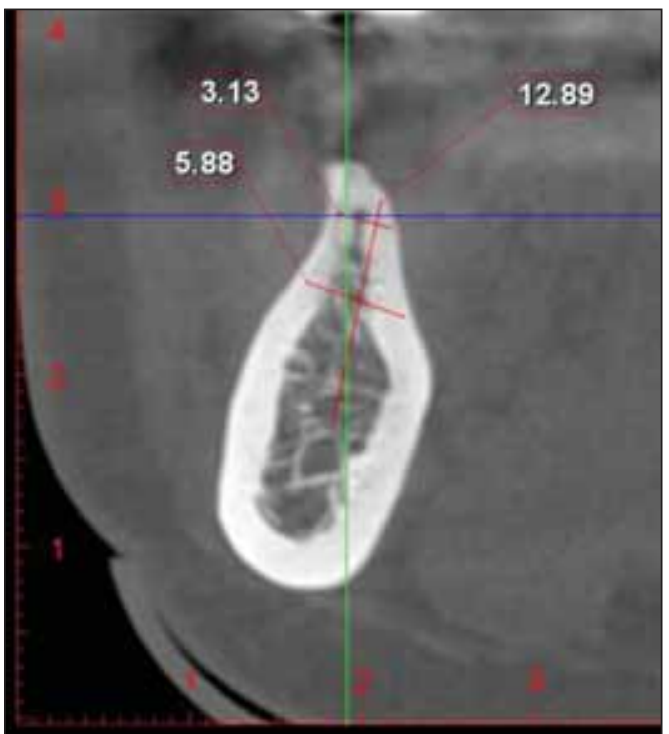

FIGURA 1. Imagine radiologică a unei creste osoase ce nu permite, din punct de vedere al dimesiunii orizontale, inserarea implanturilor în condiții de siguranță rile în care, postoperator, apar fenestraţii sau dehiscenţe în apropierea implanturilor inserate ori pentru tratamentul patologiei periimplantare (3).

Tehnica de ridge splitting este indicată în situaţia crestelor atrofice maxilare sau mandibulare, $\mathrm{cu}$ dimensiune redusă la nivel orizontal, pentru a se reface conturul osos suficient pentru inserarea ulterioară a implanturilor (4).

În cazul realizării acestei intervenţii, trebuie să se aibă în vedere faptul că, cu cât osul este mai puţin dens, cu atât procedura se realizează mai uşor şi are rezultate mai predictibile (5).

\section{OBIECTIVUL STUDIULUI}

Scopul studiului este acela de a realiza o analiză asupra ratei de succes a implanturilor inserate în zone în care osul subiacent de suport a fost îmbunătăţit prin utilizarea metodelor de augmentare osoasă.

Rezultatele determinate în studiu au fost folosite pentru a urmări, comparativ, succesul integrării implanturilor inserate după diverse metode de augmentare.

\section{MATERIAL ŞI METODĂ}

Datele necesare au fost colectate prin examinarea clinică şi radiologică (ortopantomografii sau analize computer-tomograf) a pacienţilor ce s-au

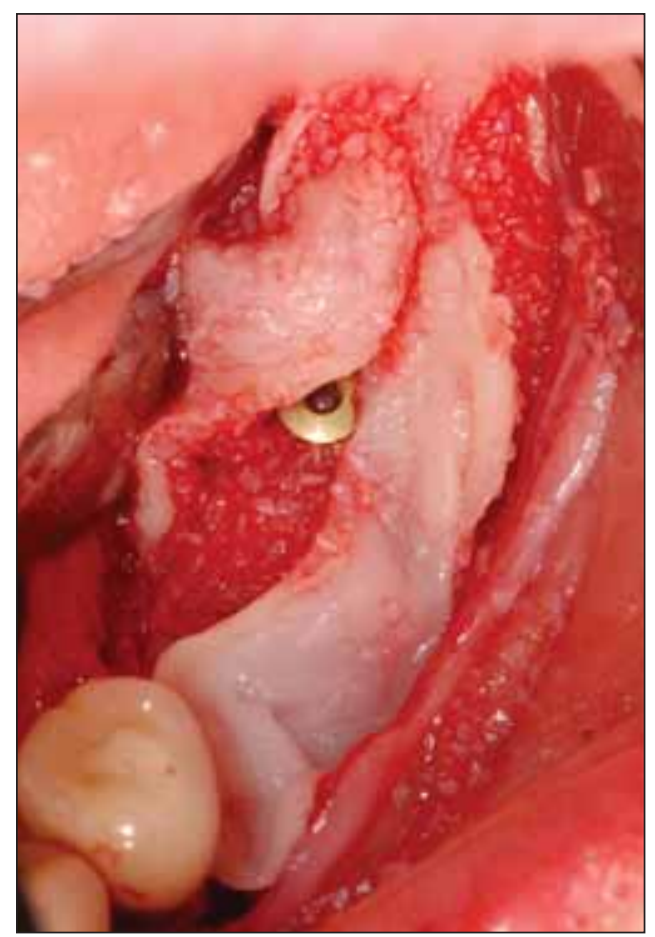

FIGURA 2. Inserarea implanturilor într-o creastă ce a beneficiat de augmentare osoasă 
prezentat în clinică şi au beneficiat de tratament implanto-protetic.

Criteriul după care au fost introduşi în studiu a fost faptul că, în cadrul tratamentului, s-a realizat inserarea a cel puţin unui implant în zone osoase care au beneficiat de realizarea unei intervenţii de augmentare a crestei osoase.

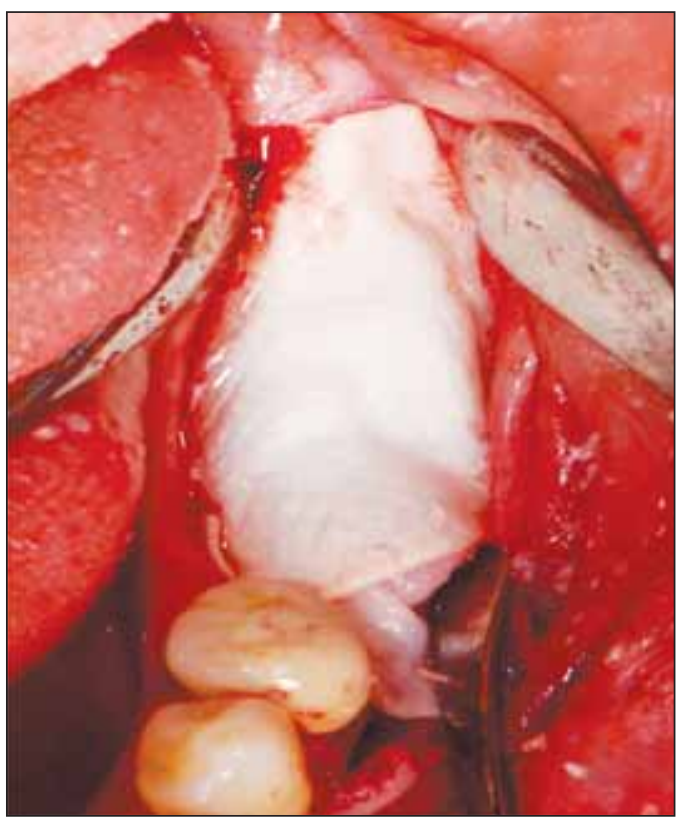

FIGURA 3. Acoperirea defectului osos augmentat, şi a implantului inserat, cu o membrană cu rol de barieră biologică.

Datele culese de la fiecare pacient au inclus:

- Aspectul ţesuturilor moi periimplantare, determinat prin examinare clinică;

- Gradul de resorbţie a ţesutului osos periimplantar, determinat prin examinare radiologică;

- Eventualele complicaţii care au apărut periimplantar.

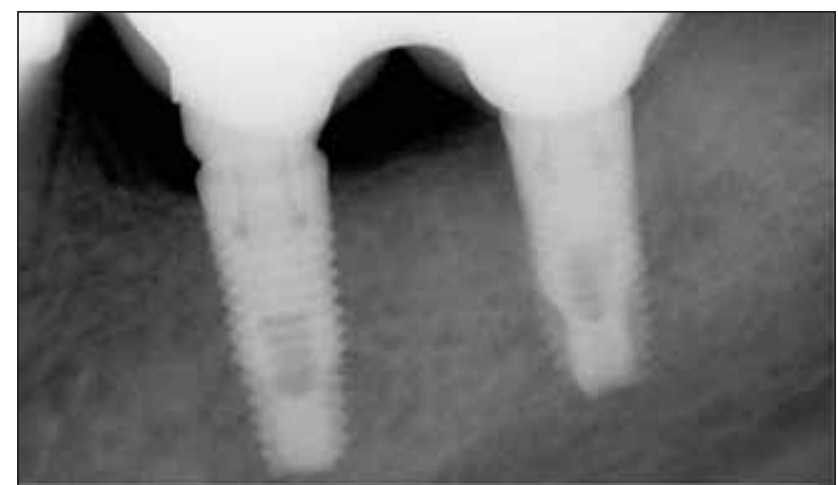

FIGURA 4. Imagine radiologică a implanturilor inserate după realizarea intervențiilor de corectare a crestei osoase deficitare
Datele au fost înregistrate în momentul examinării pacientului la aproximativ 1 an după ce implantul a fost pus în funcţiune.

S-a utilizat, pentru determinarea integrării implanturilor la nivelul ţesutului osos, computer-tomograful (CBCT). Acesta are avantajul că permite măsurarea cu exactitate a distanţelor pe o anumită secţiune, astfel că s-a putut analiza gradul de resorbţie osoasă care a apărut în decursul timpului în jurul implantului.

Rezultatele măsuratorilor au fost coroborate cu aspectul ţesuturilor moi periimplantare şi cu prezenţa/absenţa exsudatului periimplantar, pentru a putea încadra implantul într-un anumit grad de succes/eşec.

Implanturile analizate au fost împărţite în 3 categorii:

1. Implanturi inserate în creste osoase cu defecte tip dehiscenţă sau fenestraţie. Acestea au fost augmentate prin intervenţii GBR, realizate în acelaşi timp operator cu inserarea implanturilor.

2. Implanturi inserate în creste osoase cu defecte orizontale. Acestea au fost augmentate prin GBR, grefare cu os autogen sau bone splitting.

3. Implanturi inserate în creste osoase cu defecte verticale. Acestea au fost augmentate prin GBR în acelaşi timp operator sau înainte de inserarea implanturilor sau prin grefă autogenă.

\section{REZULTATE}

Resorbţia osoasă medie, măsurată în jurul implanturilor inserate în creste osoase cu defecte tip dehiscenţă/fenestraţie, care au fost augmentate prin GBR, a avut valori de $0,84 \mathrm{~mm}$.

Integrarea tisulară a implanturilor (cuantificată prin valoarea resorbţiei osoase periimplantare) a fost următoarea pentru diferite variante de augmentare, în cazul crestelor cu defecte osoase orizontale:

\begin{tabular}{|l|c|}
\hline $\begin{array}{l}\text { Resorbție osoasă în jurul implanturilor în } \\
\text { creste cu defecte orizontale }\end{array}$ & $\begin{array}{c}\text { Valoarea medie } \\
\text { (în } \mathrm{mm} \text { ) }\end{array}$ \\
\hline Augmentate prin GBR & 0,76 \\
\hline Augmentate prin grefe de os autogen & 0,67 \\
\hline Augmentate prin bone splitting & 0,77 \\
\hline
\end{tabular}

Rezultatele studiului arată că integrarea tisulară a implanturilor, măsurată prin determinarea valorii 
resorbţiei osoase periimplantare, a fost următoarea pentru diferite variante de augmentare:

\begin{tabular}{|l|c|}
\hline $\begin{array}{l}\text { Resorbție osoasă în jurul implanturilor în } \\
\text { creste cu defecte verticale }\end{array}$ & $\begin{array}{c}\text { Valoarea medie } \\
\text { în } \mathrm{mm}\end{array}$ \\
\hline $\begin{array}{l}\text { Augmentate prin GBR în acelaşi timp } \\
\text { operator cu inserarea implanturilor }\end{array}$ & 0,77 \\
\hline $\begin{array}{l}\text { Augmentate prin GBR anterior inserării } \\
\text { implanturilor }\end{array}$ & 0,71 \\
\hline Augmentate prin grefă de os autogen & 0,76 \\
\hline
\end{tabular}

\section{CONCLUZII}

Tratamentul implanto-protetic de succes presupune existenţa unui substrat osos corespunzător în care să fie inserate implanturile dentare.

Atunci când, ca urmare a edentaţiilor vechi, a traumatismelor sau a intervenţiilor chirurgicale de îndepărtare a unor procese patologice, osul de suport prezintă defecte mari, incompatibile cu inserarea implanturilor, se poate apela la o serie de proceduri ajutătoare, care să refacă cel puţin o parte din osul pierdut.
Astfel de intervenţii sunt regenerarea osoasă ghidată, utilizarea grefelor osoase sau bone splitting-ul.

Fiecare tip de intervenţie poate fi utilizat, în funcţie de cazul clinic.

S-a observat că există rate de succes mari atunci când se utilizează tehnici precum regenerarea osoasă ghidată realizată înainte de inserarea implanturilor, în cazul defectelor verticale, sau utilizarea grefelor de os autogen în cazul defectelor orizontale.

Totuşi, nu s-au decelat diferenţe semnificative între ratele de succes ale implanturilor inserate în creste cu defecte osoase orizontale, atunci când s-au folosit regenerarea osoasă ghidată, grefele de os autogen sau tehnica bone splitting.

De asemenea, nu se poate spune că există diferenţe semnificative între integrarea implanturilor în creste osoase cu defecte verticale augmentate prin regenerare osoasă ghidată, realizată anterior sau în acelaşi timp chirurgical cu inserarea implanturilor, sau prin grefare cu grefe de os autogen.

Conflict of interest: none declared Financial support: none declared

osseointegrated implants. Int J Periodontics Restorative Dent 14:496, 1994.

4. Demetriades N, Park JI, Laskarides C. Alternative bone expansion technique for implant placement in atrophic edentulous maxilla and mandible. J Oral Implantol. 2011 Aug; 37(4):463-71.

5. Misch CE, Resnik R. Misch's Avoiding Complications in Oral Implantology. Elsevier, 2018 (pg. 206).

3. Simion M, Trisi P, Piattelli A. Vertical ridge augmentation using a membrane technique associated with 